\title{
Ultrasound evaluation of schistosomiasis-related morbidity among the Xakriabá people in the state of Minas Gerais, Brazil
}

Avaliação ultrassonográfica da morbidade por esquistossomose mansoni na população indígena Xakriabá, Minas Gerais, Brasil

\section{Carolina Coimbra Marinho ${ }^{1, a}$, Aline Joice Pereira Gonçalves Nicolato ${ }^{2, b}$, Vivian Walter Reis ${ }^{2, c}$, Rosiane Cristina dos Santos $^{2, d}$, Jaime Costa Silva ${ }^{3, e}$, Henrique Pereira Faria ${ }^{2, f}$, George Luiz Lins Machado-Coelho ${ }^{2, g}$}

1. Universidade Federal de Minas Gerais (UFMG), Belo Horizonte, MG, Brazil. 2. Universidade Federal de Ouro Preto (UFOP), Ouro Preto, MG, Brazil. 3. Ministério da Saúde, Fundação Nacional de Saúde (Funasa), Brasília, DF, Brazil.

Correspondence: Dra. Carolina Coimbra Marinho. Faculdade de Medicina da UFMG - Departamento de Clínica Médica. Avenida Professor Alfredo Balena, 190, sala 246, Centro. Belo Horizonte, MG, Brazil, 30130-100. Email: carolinacmarinho@gmail.com.

a. https://orcid.org/0000-0002-0950-0322; b. https://orcid.org/0000-0002-1837-7485; c. https://orcid.org/0000-0001-5717-2880; d. https://orcid.org/0000-0001-5305-502X; e. https://orcid.org/0000-0002-7699-6831; f. https://orcid.org/0000-0002-1714-3185; g. https://orcid.org/0000-0002-9806-9721.

Received 27 March 2019. Accepted after revision 21 June 2019.

How to cite this article:

Marinho CC, Nicolato AJPG, Reis VW, Santos RC, Silva JC, Faria HP, Machado-Coelho GLL. Ultrasound evaluation of schistosomiasis-related morbidity among the Xakriabá people in the state of Minas Gerais, Brazil. Radiol Bras. 2020 Jan/Fev;53(1):7-13.

Abstract Objective: To use ultrasound to investigate the morbidity related to schistosomiasis in the Xakriabá indigenous population.

Materials and Methods: This was a field-based census study conducted in the territory of the Xakriabá people. A total of 166 individuals were invited, and 148 ( $\leq 77$ years of age) agreed to participate. Most participants underwent abdominal ultrasound, physical examination, and stool examination. Mann-Whitney $\mathrm{U}$ and chi-square tests were used for comparisons. We determined risk by calculating odds ratio $(\mathrm{OR})$ and performed logistic regression analysis.

Results: Schistosoma mansoni eggs were found in 31 (26.7\%) of the 116 stool samples examined, 22 (70.9\%) of the 31 being from individuals 4-16 years of age. The median count was 144 eggs/g of feces (interquartile range, 264). Of the 105 participants examined with ultrasound, 68 (64.8\%) had hepatomegaly (left lobe), 6 (5.7\%) had splenomegaly, and 4 (3.8\%) had portal hypertension. Egg-positive stool samples were more common in those with an enlarged left lobe $(\mathrm{OR}=3.4$; $95 \%$ confidence interval $(\mathrm{Cl})$ : 1.1-11.2; $p=0.043)$. Periportal fibrosis was found in 30 participants (28.6\%), of whom 9 (30\%) had pattern C, 10 (33.3\%) had pattern D, and $11(36.7 \%)$ had pattern Dc. Age was the only independent risk factor for fibrosis $(p=0.007)$. Fibrosis was up to nine-fold more common in alcohol drinkers than in nondrinkers ( $\mathrm{OR}=9.28 ; 95 \% \mathrm{Cl}: 2.60-33.06 ; p<0.001)$. Among the 138 participants in whom the clinical form was classified, the chronic hepatic form was identified in 54 (39.1\%), of whom 32 (59.2\%) were under 30 years of age and one (1.8\%) was hepatosplenic.

Conclusion: Schistosomiasis in the Xakriabá population is characterized by a high frequency of egg-positive stool samples, predominantly in children/adolescents, and by chronic hepatic form in the young, especially among alcohol drinkers.

Keywords: Schistosomiasis mansoni; Population groups; Ultrasonography.

Resumo Objetivo: Investigar a morbidade por esquistossomose na população indígena Xakriabá usando a ultrassonografia.

Materiais e Métodos: Estudo de campo censitário realizado na terra da população indígena Xakriabá (166 convidados; 148 participantes; idade de 0-77). Foram feitos ultrassonografia abdominal, exame físico e coproscopia (EPF). Os testes Mann-Whitney U e qui-quadrado foram usados para comparações. Foram realizadas análise de risco (odds ratio - OR) e regressão logística.

Resultados: De 116 índios com resultado de EPF, 31 (26,7\%) tiveram ovos de Schistosoma; 22/31 (70,9\%) tinham idade entre 4-16 anos. A carga parasitaria mediana foi 144 ovos/g (intervalo interquartílico: 264). De 105 examinados por ultrassom, 68 $(64,8 \%)$ tiveram lobo hepático esquerdo aumentado, 6 (5,7\%) tiveram esplenomegalia e $4(3,8 \%)$ tiveram hipertensão portal. EPF+ foi mais frequente nos indivíduos com lobo esquerdo aumentado (OR: 3,4; intervalo de confiança (IC) 95\%: 1,1-11,2; $p=0,043$ ). Fibrose periportal ocorreu em 30/105 (28,6\%) examinados, e desses 30, 9 (30\%) apresentavam padrão C, 10 (33,3\%) apresentavam padrão D e $11(36,7 \%)$ apresentavam padrão Dc. A idade foi o único fator de risco independente para fibrose $(p=0,007)$. A fibrose ocorreu até nove vezes mais em usuários de álcool que em não usuários (OR: 9,28; IC 95\%: 2,60-33,06; $p<0,001$ ). Formas crônicas ocorreram em 54/138 (39,1\%) participantes, sendo 32 dos 54 (64,8\%) em menores de 30 anos; um (1,8\%) era hepatoesplênico.

Conclusão: A esquistossomose na população Xakriabá caracteriza-se por alta positividade, predomínio em crianças e presença de formas hepáticas crônicas em jovens, especialmente entre usuários de álcool.

Unitermos: Esquistossomose mansoni; Grupos populacionais; Ultrassonografia. 


\section{INTRODUCTION}

The territory of the Xakriabá people is the largest demarcated indigenous area in the state of Minas Gerais, Brazil, where conditions are favorable for the transmission of schistosomiasis, because the vector is present and there is poor sanitation ${ }^{(1)}$. A previous parasitological survey ${ }^{(2)}$ showed ongoing transmission of Schistosoma mansoni in two rural villages within the Xakriabá territory-Dizimeiro and Peruaçu-near the Peruaçu river, in 2017. The villages are situated within the municipality of São João das Missões, $677 \mathrm{~km}$ north of the capital city of Belo Horizonte. At that time, $15 \%$ of the individuals screened tested positive and were treated with antiparasitic drugs. However, liver and spleen involvement were not studied.

In cases of schistosomiasis, examination of the liver and spleen is crucial to recognizing the risk of complications, such as upper gastrointestinal bleeding secondary to variceal rupture $^{(3)}$. Liver biopsy, the gold-standard diagnostic method for periportal fibrosis (PF), is not routinely used because it is invasive ${ }^{(4)}$. In contrast, abdominal ultrasound is noninvasive, practical and safe. It is now considered the best imaging technique to detect changes suggestive of chronic schistosomiasis in the field ${ }^{(5)}$. Nevertheless, it is a dynamic and examiner-dependent method ${ }^{(6)}$. The NiameyBelo Horizonte protocol outlines the World Health Organization (WHO) standard recommendations for ultrasound in schistosomiasis ${ }^{(7)}$. According to the protocol, if some degree of periportal thickening is observed, the image is compared with standard imaging patterns of liver parenchyma. Patterns range from $\mathrm{A}$, indicating normal parenchyma, to F, characterized by highly echogenic, often conglomerated, bands extending from the main portal vein and its bifurcation to the liver surface, which may be retracted. Pattern $\mathrm{B}$ is characterized by diffuse echogenic foci; pattern $\mathrm{C}$ shows echogenic rings corresponding to the pipe-stem fibrosis seen in a perpendicular scan; and patterns D and E are characterized by progressive echogenic thickening and patches extending around the portal bifurcation and the main stem. Mixed patterns can also be seen ${ }^{(7)}$. However, it should be borne in mind that the intensity of fibrosis on ultrasound may not correlate with disease severity ${ }^{(8)}$.

The objective of this study was to investigate positivity for schistosomiasis and parasite burden, as well as the frequency of liver and spleen involvement on ultrasound, in the Xakriabá population. We also attempted to determine whether the chronic forms correlate with clinical and epidemiological factors.

\section{MATERIALS AND METHODS}

A descriptive cross-sectional field-based study was conducted to investigate the frequency and morbidity related to schistosomiasis in Xakriabá indigenous population. All 166 residents of Dizimeiro and Peruaçu were invited; 148 (89\%) participated. Participants 5-and-older had epidemiological, clinical, parasitological, and ultrasound data recorded. Children under 5 had parasitological examination only.

This work is part of a study designed to assess the health of indigenous populations in Minas Gerais, approved by the National Research Ethics Council (Ruling no. 902/2006; Registration no. 12827) and by the National Indigenous Foundation (Authorization no. 73/CGEP/06). Permission was also obtained from local indigenous leaders and from the local council for the health of indigenous populations. Participants who tested positive for intestinal parasites were treated with antiparasitic drugs. All health abnormalities were officially reported to local authorities.

\section{Parasitology}

To diagnose infection with S. mansoni, we employed the TF-test stool test (Bio-Brasil Biotecnologia, Anápolis, Brazil). Approximately $1 \mathrm{~g}$ of feces was examined in a set of three tubes containing preservative solution ( $10 \%$ formalin) processed with $3 \mathrm{~mL}$ of ethyl-acetate and a drop of neutral detergent. The tubes were connected to a centrifuge tube and spun at 1500 rpm for 1 min (Elektra GoldLine; Laborline, São Paulo, Brazil). The supernatant was discarded, and the pellet was resuspended in distilled water, after which it was examined by light microscopy at magnifications of $\times 10$ and $\times 40$ ( 3 slides per sample). This method was chosen in order to simplify the logistics in the field. Samples were collected in preservative solution and transported to the research laboratory for analysis. Participants testing positive for $S$. mansoni were invited to provide a fresh sample for quantitative analysis by the Kato-Katz method ${ }^{(9)}$, with a commercially available kit (Kato-Katz CoproKit; Campinas Medical, Campinas, Brazil). Stool samples (standard weight, $41.7 \mathrm{mg}$ each), collected in a plastic vial, were processed, washed for $30 \mathrm{~min}$, and examined by light microscopy (at $\times 10$ and $\times 40,3$ slides per sample). Samples with viable $S$. mansoni eggs were labeled as positive. The parasite burden, defined as the number of eggs per gram (eggs/g) of feces, was calculated by multiplying the mean egg count of each slide by 24 . Infection was graded, as recommended by the $\mathrm{WHO}^{(10)}$, as mild (1-99 eggs/g), moderate (100-399 eggs $/ \mathrm{g})$ or intense $(\geq 400 \mathrm{eggs} / \mathrm{g})$. The presence of eggs of other parasites was recorded.

\section{Ultrasound}

A trained radiologist, who was blinded to the parasitological and clinical findings, used a portable ultrasound system (Logiq i; GE Healthcare, Chalfont St. Giles, UK) with a multifrequency $(2.5-5 \mathrm{MHz})$ convex transducer. Participants $\geq 5$ years of age underwent fasting ultrasound in accordance with the WHO guidelines for ultrasound in schistosomiasis ${ }^{(7)}$. Measures were adjusted for height and classified as normal or increased. Hepatomegaly, splenomegaly, and portal hypertension (PH) were diagnosed when the left lobe of the liver, spleen, and portal vein measures, respectively, were above adjusted reference 
values. The reference measure for gallbladder wall thickness was $<3 \mathrm{~mm}$ for persons weighing $\leq 30 \mathrm{~kg}$ and $<4$ $\mathrm{mm}$ for those weighing $>30 \mathrm{~kg}^{(5)}$. The reference measure for the internal diameter of the splenic and superior mesenteric veins was $<9 \mathrm{~mm}$ for both ${ }^{(11)}$. A diagnosis of PF was made when ultrasound images of the liver were consistent with the WHO patterns C, D, E, F, or any combination of those $^{(7)}$. As previously described ${ }^{(12)}$, the PF patterns were grouped for analysis as "absent" (A or B) or "mild"(C, D, or Dc). Figure 1 shows images characteristic of the standard imaging patterns of fibrosis.

\section{Clinical forms}

Identification of the chronic forms of schistosomiasis was based on the parasitological and ultrasound findings. Hepatointestinal schistosomiasis was defined as a positive TF-test result, with or without PF on ultrasound, and no PH or splenomegaly. The hepatosplenic form was defined as $\mathrm{PF}$ with splenomegaly, with or without $\mathrm{PH}$ on ultrasound. Participants with PF on ultrasound and a negative or unavailable stool test result were classified as having chronic schistosomiasis because of the high local rate of positivity $^{(13)}$. Participants with a negative or unavailable stool test result and without PF were classified as not having schistosomiasis.

\section{Epidemiology}

We collected data related to demographic characteristics, contact with natural waters, previous treatment for schistosomiasis, risk factors for chronic liver diseases, and the physical examination. Alcohol drinking was assessed as "yes" or "no".

\section{Statistical analysis}

The IBM SPSS Statistics software package, version 22.0 (IBM Corp., Armonk, NY, USA) was used for data storage and analysis. Normal distribution was verified by the Shapiro-Wilk test. Continuous variables are presented as median and interquartile range (IQR); the Mann-Whitney $U$ test was used for comparisons. Categorical variables are presented as absolute and relative frequencies; the chi-square test was used for comparisons. For risk analysis, we calculated odds ratios (ORs). A logistic regression model was used for the multivariate analysis. Variables with significance level of 0.2 were included in the multivariate model. The level of significance was set at 0.05 .
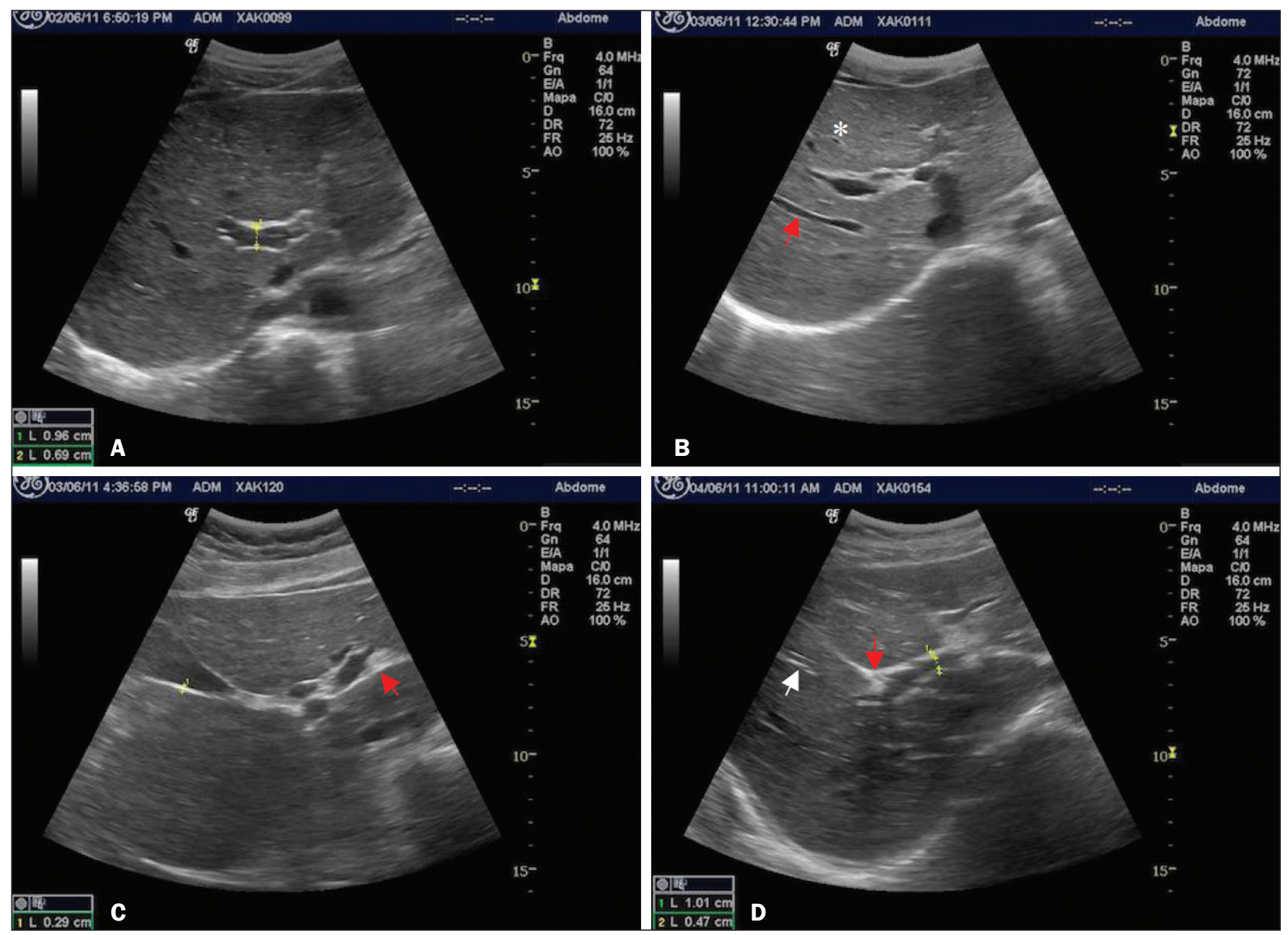

Figure 1. Liver parenchyma patterns. A: Pattern B, starry sky. B: Pattern C, rings (asterisk) and pipe-stem fibrosis (arrow). C: Pattern D, a ruff around the portal bifurcation (arrow). D: Pattern Dc, mixed pattern with a ruff (red arrow) and pipe-stem fibrosis (white arrow). 


\section{RESULTS}

\section{Clinical findings}

We evaluated 148 individuals $\leq 77$ years of age, with a median age of 14 years (IQR, 25 years). Of the 148 participants, $70(47.3 \%)$ were women. Table 1 presents the descriptive statistics of the epidemiological, physical examination, and ultrasound findings. In all cases in which the liver was palpable, it had a normal consistency and a smooth edge. No ascites, abdominal collateral circulation, jaundice, deterioration in general health, or palpable spleen were detected. There were no statistical associations between positivity for Schistosoma eggs and the clinical findings.

\section{Parasitology}

Stool samples were available for 116 (78.4\%) of the 148 participants. Among those 116 participants, positivity for any parasite was identified in $104(89.0 \%)$ and S. mansoni was identified in $31(26.7 \%)$. The ages of the 31 individuals testing positive for $S$. mansoni ranged from 4 to 31 years, and $22(70.9 \%)$ were between 4 and 16 years of age. Of the 31 participants with schistosomiasis, 15 (48.4\%) had an egg-positive stool sample and provided a fresh sample for

Table 1-Descriptive statistics of residents of Xakriabá territory $(n=148)$ in the state of Minas Gerais, Brazil.

\begin{tabular}{|c|c|c|c|}
\hline Variable & Valid data* & $\mathrm{N}$ & $(\%)$ \\
\hline \multicolumn{4}{|l|}{ Years of schooling } \\
\hline$<1$ & 114 & 14 & $(32.5)$ \\
\hline $1-8$ & 114 & 69 & $(60.5)$ \\
\hline$>9$ & 114 & 8 & (7.1) \\
\hline \multicolumn{4}{|l|}{ Occupation } \\
\hline Teacher/health care worker & 111 & 4 & (3.6) \\
\hline Homemaker & 111 & 11 & $(9.9)$ \\
\hline Farmer & 111 & 26 & $(23.4)$ \\
\hline Student & 111 & 36 & $(32.4)$ \\
\hline \multicolumn{4}{|l|}{ Risk factors for chronic liver disease } \\
\hline Blood transfusion & 124 & 3 & $(2.4)$ \\
\hline Gastrointestinal bleeding & 123 & 38 & $(30.9)$ \\
\hline Alcohol drinking & 122 & 51 & $(41.8)$ \\
\hline Contact with natural waters & 110 & 110 & $(100.0)$ \\
\hline Treatment for schistosomiasis & 80 & 58 & $(72.5)$ \\
\hline Overweight/obese & 120 & 24 & $(20.0)$ \\
\hline \multicolumn{4}{|l|}{ Palpation of the liver } \\
\hline Palpable left lobe & 104 & 15 & $(14.4)$ \\
\hline Palpable right lobe & 104 & 16 & $(15.4)$ \\
\hline \multicolumn{4}{|l|}{ Enlarged features $^{\dagger}$ (median, IQR) } \\
\hline Left liver lobe (8.7 cm, 2.8) & 105 & 68 & $(64.8)$ \\
\hline Spleen $(8.6 \mathrm{~cm}, 1.7)$ & 105 & 6 & $(5.7)$ \\
\hline Portal vein diameter $(7.8 \mathrm{~mm}, 2.6)$ & 105 & 4 & $(3.8)$ \\
\hline Gallbladder wall thickness (2.4 mm, 0.8) & 105 & 1 & $(0.9)$ \\
\hline \multicolumn{4}{|l|}{ Liver fibrosis pattern ( 7 ) } \\
\hline C & 30 & 9 & $(30.0)$ \\
\hline $\mathrm{D}$ & 30 & 10 & (33.3) \\
\hline Dc & 30 & 11 & $(36.7)$ \\
\hline
\end{tabular}

* Total number of individuals for whom valid data were obtained. ${ }^{\dagger}$ On abdominal ultrasound. quantitative analysis. Three of those 15 samples were found to contain no eggs. Egg counts ranged from 0 to 384, with a median of 144 (IQR, 264).

\section{Ultrasound}

Ultrasound records were available for $105(70.9 \%)$ of the 148 participants. Of those 105, 30 (28.6\%) had PF. Fibrosis patterns C, D, and Dc were detected. Of the 30 participants with PF, $8(26.5 \%)$ were in the 10 - to 19 -year age group and $20(66.7 \%)$ were in the 40- to 49-year age group. The risk of PF was tenfold higher in the $\geq 30$-year age group than in the $<10$-year age group $(\mathrm{OR}=10 ; 95 \%$ confidence interval (CI): $2.0-50.4 ; p=0.001)$. Neither an egg-positive stool sample nor previous treatment for schistosomiasis was found to be associated with splenomegaly or PF, nor was PF found to be associated with $\mathrm{PH}$ or splenomegaly. One participant had splenomegaly and the Dc pattern of PF, without PH (Figure 2).

There were no significant differences between the participants with and without an egg-positive stool sample, in terms of the ultrasound measures. However, an egg-positive stool sample was 3.4 times more common in those with an enlarged left lobe of the liver $(\mathrm{OR}=33.4$; 95\% CI: $1.1-11.2 ; p=0.043)$.

Of the 148 participants, $4(2.8 \%)$ had PH. Three of those four had an egg-positive stool sample. There was no significant difference between those with and without $\mathrm{PH}$ in terms of the median age-11.5 (IQR, 20) vs. 17 (IQR, $25) ; p=0.267$. No collateral circulation was detected in any of the participants.

Alcohol drinkers were at a 3.5-fold greater risk of having $\mathrm{PF}(\mathrm{OR}=3.54 ; 95 \% \mathrm{CI}: 1.4-8.8 ; p=0.009$, data not shown). When stratified by age, the risk of PF was nine times higher in alcohol drinkers $\geq 30$ years of age than in nondrinkers $<19$ years of age (Table 2 ).

For $83(56 \%)$ of the 148 participants, ultrasound and parasitological results were both available for multivariate modeling. Age, alcohol consumption, PH, and enlarged left lobe of the liver, adjusted for gender and egg positivity, were included in the risk analysis for PF $(p<0.2$ for all). Age remained the only independent risk factor ( $p=$ 0.007). No independent risk factors for PH were detected.

It was possible to classify the clinical form of schistosomiasis in 138 (93.2\%) of the 148 participants. Among those 138 individuals, chronic forms were identified in $54(39.1 \%)$, of whom $32(59.2 \%)$ were under 30 years of age —median age, 15 (IQR, 25) — and 53 (98.1\%) had the hepatointestinal form, the remaining individual, a 21 -yearold man, having the hepatosplenic form.

\section{DISCUSSION}

To our knowledge, this was the first field-based study using ultrasound to describe schistosomiasis-related morbidity in an indigenous population living in demarcated lands in Brazil. The Xakriabá land is situated in an endemic 

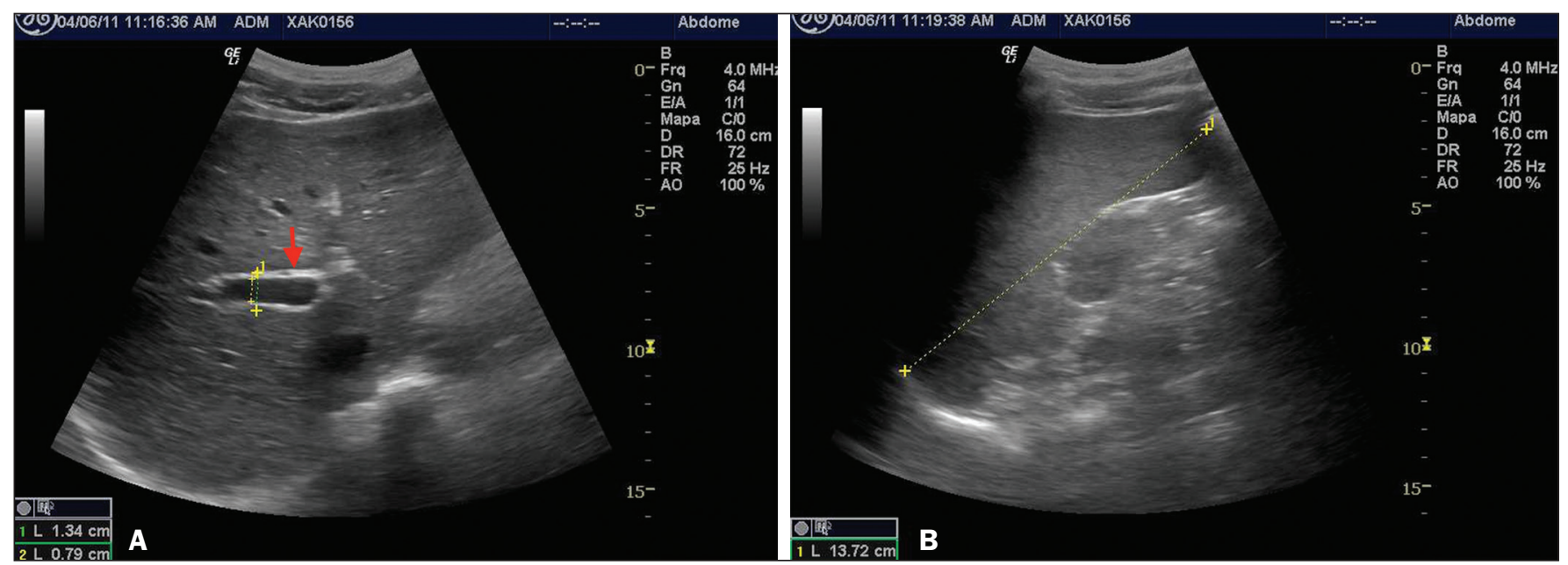

Figure 2. A: PF pattern D (arrow): periportal thickening without PH (measures: 1. portal vein outer diameter, dashed line 1, 1.34 cm; and 2. portal vein inner diameter, dashed line 2, $0.79 \mathrm{~cm}$ ). B: Spleen enlargement (dashed line 1, 13.72 cm).

Table 2-Prevalence and risk of PF, by age group and alcohol drinking, among residents of Xakriabá territory $(n=103)$ in the state of Minas Gerais, Brazil.

\begin{tabular}{|c|c|c|c|c|c|c|c|}
\hline \multirow{3}{*}{$\begin{array}{l}\text { Alcohol } \\
\text { drinking }\end{array}$} & \multirow{3}{*}{$\begin{array}{c}\text { Age } \\
\text { (years) }\end{array}$} & \multicolumn{4}{|c|}{$\mathrm{PF}$} & \multirow[b]{3}{*}{ OR $(95 \% \mathrm{Cl})$} & \multirow[b]{3}{*}{$P$} \\
\hline & & \multicolumn{2}{|r|}{ No } & \multicolumn{2}{|r|}{ Yes } & & \\
\hline & & $\mathrm{N}$ & $(\%)$ & $\mathrm{N}$ & $(\%)$ & & \\
\hline \multirow{3}{*}{ No } & $5-19$ & 30 & (83.3) & 6 & $(16.7)$ & 1 & - \\
\hline & $20-29$ & 4 & (80.0) & 1 & $(20.0)$ & $1.25(0.12-13.24)$ & 0.85 \\
\hline & $\geq 30$ & 10 & (83.3) & 2 & $(16.7)$ & $1.00(0.17-5.77)$ & 1.00 \\
\hline \multirow{3}{*}{ Yes } & $5-19$ & 16 & $(76.2)$ & 5 & $(23.8)$ & $1.56(0.41-5.90)$ & 0.51 \\
\hline & $20-29$ & 6 & $(66.7)$ & 3 & (33.3) & $2.50(0.48-12.88)$ & 0.26 \\
\hline & $\geq 30$ & 7 & (35.0) & 13 & $(65.0)$ & $9.28(2.60-33.06)$ & $<0.001$ \\
\hline
\end{tabular}

area targeted by the Brazilian National Schistosomiasis Control Program ${ }^{(14)}$. The fact that $89 \%$ of the residents participated in the present study indicates the level of concern on the part of the population and local leaders. We detected a high $(26.7 \%)$ frequency of egg-positive schistosomiasis and a high $(39.1 \%)$ prevalence of the chronic forms. Despite the low frequency of the hepatosplenic form $(1.8 \%)$, the high frequency of the hepatointestinal form $(38.4 \%)$, together with the young age of affected subjects, implies a high risk of developing the severe form of the disease $\mathrm{e}^{(15,16)}$. Positivity for any parasite was an alarming $89 \%$, and polyparasitism was common (data not shown). Also remarkable is the high frequency of alcohol drinking at ages as young as 10 years.

The $26.7 \%$ rate of positivity for Schistosoma eggs in this survey, performed in 2011, was more than three times higher than the annual national averages reported between 1990 to $2010^{(17)}$. This finding is consistent with those of a previous study involving the same population ${ }^{(2)}$. Four years after the mass treatment of children and adolescents, the transmission cycle continues, indicating a failure to improve local sanitation. A few previous studies have reported the frequency of schistosomiasis in other indigenous peoples in Brazil, all in Minas Gerais. The rate of positivity for schistosomiasis among the Maxakali people was reported to be $23.7 \%$ in $2009^{(18)}$ and $51.9 \%$ in $2013^{(19)}$; among the Pataxó people, it was reported to be $5.0 \%$ in $2012^{(20)}$. No liver or spleen involvement was reported in any of those studies.

In the present study, an egg-positive stool sample was more common in children 4-16 years of age. This finding is in agreement with those of a previous study involving the nonindigenous population of another endemic area in Minas Gerais ${ }^{(16)}$. The distribution of positivity by age in endemic areas typically shows higher frequencies among preschool- and school-age children than among adolescents and adults. Therefore, school-age children have been the target of schistosomiasis control programs ${ }^{(21)}$. Current guidelines recommend mass treatment of schoolage children in areas where positivity is above $25 \%$ (17).

In our sample, parasite burdens were moderate. However, this finding must be interpreted with caution because only 15 samples ( 3 slides each) were quantitatively assessed. Therefore, the parasitic burden might have been underestimated, given that increasing the number of samples has been shown to increase the accuracy of the method ${ }^{(22)}$. One study employing the same method achieved a sensitivity of $59.7 \%$ by examining at least 2 slides of 3 samples per person ${ }^{(23)}$.

Periportal fibrosis on ultrasound in subjects living in endemic areas indicates a high probability of schistosomiasis $^{(8)}$. If the appropriate guidelines are followed, ultrasound is a highly accurate method for diagnosing schistosomiasisrelated morbidity ${ }^{(5)}$. However, differential diagnoses should be considered ${ }^{(11)}$. In the present study, the frequency of PF was $28.3 \%$. Although chronic viral hepatitis was not ruled out, we identified no changes related to other chronic liver diseases, such as cirrhosis, steatosis, and cysts. Because the study population lived in an endemic area with early, recurrent exposure to infection, the identification of PF by ultrasound, even if the stool sample tested negative, was strongly suggestive of schistosomiasis ${ }^{(6)}$. In addition, we found no 
association between PH and splenomegaly. This is in keeping with the findings of a previous study showing that the intensity of PF may not correlate with the clinical profile of the patient ${ }^{(8)}$. Other causes of $\mathrm{PH}$ and splenomegaly, such as portal vein thrombosis and visceral leishmaniasis, were not investigated in our survey. Additional diagnostic workup would be useful to exclude other diagnoses.

We found that an egg-positive stool sample and PF both showed a positive correlation with age, a finding consistent with lifelong recurrent infections, as described by others ${ }^{(15,16)}$. Similar results were obtained in a comparative study of schistosomiasis conducted in Egypt and Kenya $^{(15)}$. Studies conducted in Mali ${ }^{(24)}$ and Tanzania ${ }^{(25)}$ reported that PF was identified in $8 \%$ of children 5-9 years of age. That indicates that transmission is established and stable in the area, as well as that PF begins in early childhood.

The assessment of PF, PH, hepatomegaly, and splenomegaly, as recommended by the WHO, rely on quantitative and qualitative information ${ }^{(7)}$. Regarding PF, quantitative assessment of the thickness of portal vein wall, particularly in the secondary branches, proved to be impractical. It has been considered too time-consuming, as well as being complex, and has been shown to have low reproducibility ${ }^{(5)}$. Findings of enlarged secondary branches did not add clinically relevant information in our study.

Enlargement of the left lobe of the liver has long been recognized as a characteristic of hepatosplenic schistosomiasis ${ }^{(26)}$. This finding is usually ascribed to increased blood flow to the left lobe due to $\mathrm{PH}^{(27)}$. However, we found that an enlarged left lobe of the liver did not correlate with $\mathrm{PH}$, although it did correlate with an egg-positive stool sample. That suggests that the migration of eggs into small portal tributaries produces a similar increase in blood flow to the left lobe in the hepatointestinal form, even before development of full hepatosplenic form.

Evaluation of the liver by imaging methods has been the subject of various recent studies in the radiology literature of Brazil ${ }^{(28-32)}$. The availability of affordable, good quality ultrasound machines has allowed the development of focused point-of-care ultrasound protocols applicable to tropical diseases. Ultrasound evaluation of schistosomiasis has proved practical and clinically meaningful $^{(5,6,16)}$. Although full application of the WHO protocol might be complicated and time-consuming, a simplified point-of-care ultrasound protocol with a few standardized liver and spleen views could help detect severe disease and determine the risk of complications. The presence of PF pattern D, E, or F would indicate the need for screening of esophageal varices by endoscopy. The diagnosis of $\mathrm{PH}$, hepatomegaly, and splenomegaly can be made by simple measures in standard views ${ }^{(33)}$.

In the present study, alcohol drinking was positively associated with PF and represented an independent risk factor for liver changes, especially in individuals over 30 years of age. Unquantified alcohol consumption was also identified as a risk factor for PF in Tanzania ${ }^{(25)}$. In a study involving the nonindigenous population of another endemic area in Minas Gerais ${ }^{(34)}$, alcohol abuse, defined as consumption $>60 \mathrm{~g} /$ day, was associated with periportal thickening in schistosomiasis. Doppler ultrasound might be useful in making the differential diagnosis between schistosomiasisrelated and alcohol-related cirrhosis. Azeredo et al. ${ }^{(35)}$ reported a positive association between maximal flow velocity in the portal vein and hepatic artery peak systolic velocity in patients with schistosomiasis-induced PF, whereas that association was negative in patients with cirrhosis. However, Doppler ultrasound failed to identify the hepatic artery in over $60 \%$ of the patients with PF in that study.

We detected chronic schistosomiasis in nearly $40 \%$ of the individuals in our sample. The hepatosplenic form was identified in only one individual, corresponding to a prevalence of $1.8 \%$, which is lower than the $10 \%$ typically reported in endemic areas ${ }^{(16,34)}$. However, that case occurred in an individual under 30 years of age. Participants with the hepatointestinal form were also young and are therefore at high risk of developing the hepatosplenic form in the future. A retrospective study conducted in Minas Gerais after the implementation of schistosomiasis control programs found an overall decrease in morbidity. In that study, the median age of the individuals with the hepatosplenic form was 45 years $^{(14)}$. That underscores the urgent need for disease control to protect new generations from this incapacitating, life-threatening disease.

\section{Limitations}

Our study has some limitations. The failure to undertake a complete differential diagnostic workup for chronic liver diseases, especially viral hepatitis, was a major limiting factor. Serological analysis would have been useful in resolving diagnostic uncertainty. However, because blood collection was not foreseen before ethics approval, it could not be performed. Another limitation was that alcohol intake was not quantified. Although it might have allowed more detailed inferences on the alcohol and PF association, alcohol intake is often subject to memory bias. Additionally, alcohol drinking is usually taboo among indigenous populations.

\section{CONCLUSION}

Among the Xakriabá people, the rate of positivity for schistosomiasis was higher than the national average. Moderate parasite burdens were detected (median 144 eggs/g). Egg-positive stool samples were most common among school-age children, and PF was found in children and adolescents. Age was the only independent risk factor for PF, and alcohol drinking was significantly associated with the development of liver fibrosis. These findings suggest that the Xakriabá people are not given sufficient attention in official programs designed to reduce morbidity related to schistosomiasis. 


\section{Acknowledgments}

We are grateful to the Distrito Sanitário Especial Indígena Minas Gerais/Espírito Santo (DSEIMG/ES), for the logistical support provided. This study was supported by a grant from the Fundação de Amparo à Pesquisa de Minas Gerais (Fapemig; Grant no. APQ01161-10).

\section{REFERENCES}

1. Pena JL, Heller L, Dias-Junior CS. A população Xakriabá, Minas Gerais: aspectos demográficos, políticos, sociais e econômicos. Rev Bras Est Pop. 2009;26:51-9.

2. Carvalho-Siqueira GL, Bakolis I, Bahia MT, et al. Prevalence of intestinal parasites among children 13-and-under residents in the indigenous land of Xakriabá, Brazil. Arch Epidemiol - AEPD. 2017;110:1-9.

3. Vennervald BJ, Dunne DW. Morbidity in schistosomiasis: an update. Curr Opin Infect Dis. 2004;17:439-47.

4. Voieta I, Queiroz LC, Andrade LM, et al. Imaging techniques and histology in the evaluation of liver fibrosis in hepatosplenic schistosomiasis mansoni in Brazil: a comparative study. Mem Inst Oswaldo Cruz. 2010;105:414-21.

5. Richter J, Domingues AL, Barata CH, et al. Report of the second satellite symposium on ultrasound in schistosomiasis. Mem Inst Oswaldo Cruz. 2001;96 Suppl:151-6.

6. Prata A, Ruiz-Guevara R, Antunes CM, et al. Comparison between clinical and ultrasonographic findings in cases of periportal fibrosis in an endemic area for schistosomiasis mansoni in Brazil. Rev Soc Bras Med Trop. 2010;43:129-34.

7. Richter J, Hatz C, Campagne G, et al. Ultrasound in schistosomiasis: a practical guide to the standardized use of ultrasonography for the assessment of schistosomiasis related morbidity. Geneva, Switzerland: World Health Organization; 1996.

8. Lambertucci JR. Revisiting the concept of hepatosplenic schistosomiasis and its challenges using traditional and new tools. Rev Soc Bras Med Trop. 2014;47:130-6.

9. Katz N, Chaves A, Pellegrino J. A simple device for quantitative stool thick-smear technique in schistosomiasis mansoni. Rev Inst Med Trop São Paulo. 1972;14:397-400.

10. World Health Organization. Prevention and control of schistosomiasis and soil-transmitted helminthiasis. Geneva, Switzerland: World Health Organization; 2002.

11. Pinto-Silva RA, Queiroz LC, Azeredo LM, et al. Ultrasound in schistosomiasis mansoni. Mem Inst Oswaldo Cruz. 2010;105:479-84.

12. Marinho CC, Bretas T, Voieta I, et al. Serum hyaluronan and collagen IV as non-invasive markers of liver fibrosis in patients from an endemic area for schistosomiasis mansoni: a field-based study in Brazil. Mem Inst Oswaldo Cruz. 2010;105:471-8.

13. Lambertucci JR, Santos Silva LC, Andrade LM, et al. Imaging techniques in the evaluation of morbidity in schistosomiasis mansoni. Acta Trop. 2008;108:209-17.

14. Drummond SC, Pereira SR, Silva LC, et al. Schistosomiasis control program in the state of Minas Gerais in Brazil. Mem Inst Oswaldo Cruz. 2010;105:519-23.

15. King CH, Magak P, Salam EA, et al. Measuring morbidity in schistosomiasis mansoni: relationship between image pattern, portal vein diameter and portal branch thickness in large-scale surveys using new WHO coding guidelines for ultrasound in schistosomiasis. Trop Med Int Health. 2003;8:109-17.

16. Lambertucci JR, Cota GF, Pinto-Silva RA, et al. Hepatosplenic schistosomiasis in field-based studies: a combined clinical and sonographic definition. Mem Inst Oswaldo Cruz. 2001;96 Suppl: $147-50$.
17. Brasil. Ministério da Saúde. Plano integrado de ações estratégicas de eliminação da hanseníase, filariose, esquistossomose e oncocercose como problema de saúde pública, tracoma como causa de cegueira e controle das geohelmintíases - plano de ação 2011-2015. Brasilia, DF: Ministério da Saúde; 2012.

18. Assis EM, Olivieria RC, Moreira LE, et al. Prevalence of intestinal parasites in the Maxakali indigenous community in Minas Gerais, Brazil, 2009. Cad Saúde Pública. 2013;29:681-90.

19. Nacife MBPESL, Siqueira LMV, Martins R, et al. Prevalence of schistosomiasis mansoni in indigenous Maxakali villages, Minas Gerais, Brazil. Rev Inst Med Trop São Paulo. 2018;60:e26.

20. Assunção RDL. Prevalência de enteroparasitoses e estado nutricional do povo indígena Pataxó dos municípios de Carmésia e Itapecerica, Minas Gerais. [Dissertação]. Governador Valadares, MG: Univale; 2012.

21. Rodrigues LC, Wheeler JG, Shier R, et al. Predicting the community prevalence of schistosomiasis mansoni from the prevalence among 7- to 14-year-olds. Parasitology. 2000;121 Pt 5:507-12.

22. Enk MJ, Lima AC, Drummond SC, et al. The effect of the number of stool samples on the observed prevalence and the infection intensity with Schistosoma mansoni among a population in an area of low transmission. Acta Trop. 2008; 108:222-8.

23. Siqueira LM, Coelho PM, Oliveira AA, et al. Evaluation of two coproscopic techniques for the diagnosis of schistosomiasis in a lowtransmission area in the state of Minas Gerais, Brazil. Mem Inst Oswaldo Cruz. 2011;106:844-50.

24. Koukounari A, Sacko M, Keita AD, et al. Assessment of ultrasound morbidity indicators of schistosomiasis in the context of large-scale programs illustrated with experiences from Malian children. Am J Trop Med Hyg. 2006;75:1042-52.

25. Malenganisho WL, Magnussen P, Friis H, et al. Schistosoma mansoni morbidity among adults in two villages along Lake Victoria shores in Mwanza District, Tanzania. Trans R Soc Trop Med Hyg. 2008;102:532-41.

26. Cerri GG, Alves VA, Magalhães A. Hepatosplenic schistosomiasis mansoni: ultrasound manifestations. Radiology. 1984;153:777-80.

27. Pereira LM, Domingues AL, Spinelli V, et al. Ultrasonography of the liver and spleen in Brazilian patients with hepatosplenic schistosomiasis and cirrhosis. Trans R Soc Trop Med Hyg. 1998;92:639-42.

28. Parente DB, Oliveira Neto JA, Araújo ALE, et al. Fat-containing liver lesions: a pictorial essay. Radiol Bras. 2018;51:52-7.

29. Lahan-Martins DL, Perales SR, Gallani SK, et al. Microvascular invasion in hepatocellular carcinoma: is it predictable with quantitative computed tomography parameters? Radiol Bras. 2019;52:287-92.

30. Nunes TF, Barbosa FCP, Tibana TK, et al. Pyogenic liver abscess as a late complication after embolization of a hepatic adenoma. Radiol Bras. 2019;52:134-5.

31. Alves AMA, Torres US, Velloni F, et al. The many faces of primary and secondary hepatic lymphoma: imaging manifestations and diagnostic approach. Radiol Bras. 2019;52:325-30.

32. Tibana TK, Grubert RM, Fornazari VAV, et al. The role of percutaneous transhepatic biliary biopsy in the the diagnosis of patients with obstructive jaundice: an initial experience. Radiol Bras. 2019;52:222-8.

33. Bélard S, Tamarozzi F, Bustinduy AL, et al. Point-of-care ultrasound assessment of tropical infectious diseases-a review of applications and perspectives. Am J Trop Med Hyg. 2016;94:8-21.

34. Cota GF, Pinto-Silva RA, Antunes CM, et al. Ultrasound and clinical investigation of hepatosplenic schistosomiasis: evaluation of splenomegaly and liver fibrosis four years after mass chemotherapy with oxamniquine. Am J Trop Med Hyg. 2006;74:103-7.

35. Azeredo LA, Queiroz LC, Marinho CC, et al. Sonographic and hemodynamic findings of schistosomiasis mansoni: Doppler sonography assessment in endemic areas. Radiol Bras. 2010;43:69-76. 